\title{
Recent Advances in Ruthenium-Catalyzed Carbene/Alkyne Metathesis (CAM) Transformations
}

\author{
Damián Padín \\ Jesús A. Varela \\ Carlos Saá*
}

Centro Singular de Investigación en Química Biolóxica e Materiais Moleculares (CiQUS), Departamento de Química Orgánica, Universidade de Santiago de Compostela, 15782 Santiago de Compostela, Spain

\section{carlos.saa@usc.es}

Click here to insert a dedication.

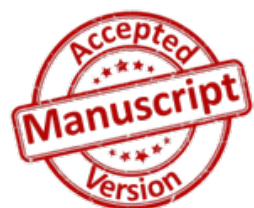

This article may be used for non-commercial purposes in accordance with Thieme Terms and Conditions for self-archiving.

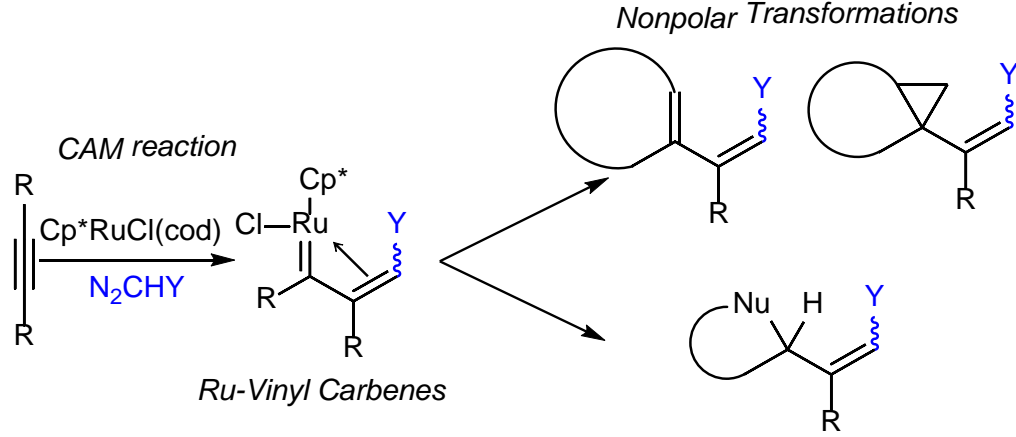

Polar Transformations

\section{Received:
Accepted:
Published online:}

Abstract Carbene intermediates have shown versatile applications in modern synthetic chemistry. Catalytic ruthenium carbene/alkyne metathesis (CAM) with readily available substrates renders an efficient procedure for the in situ generation of ruthenium vinyl carbene intermediates. Here, recent advances in synthetic applications of ruthenium-catalyzed carbene/alkyne metathesis (CAM) are highlighted.

1 Introduction

2 Ruthenium Vinyl Carbenes Through Carbene/Alkyne Metathesis (CAM) 3 Nonpolar Transformations of Ruthenium Vinyl Carbenes 4 Polar Transformations of Ruthenium Vinyl Carbenes 5 DFT Studies on the Stereoselectivity of the CAM Reaction 6 Conclusions

Key words alkynyl derivatives, carbenes, cyclization, heterocycles, metathesis, vinyl ruthenium carbenes

\section{Introduction}

The complexation of the neutral, divalent, $\mathrm{sp}^{2}$-hybridized, $6 \mathrm{e}^{-}-$ carbon atom of carbenes to a metal center entails a significant stabilization of the otherwise extremely reactive intermediate. In this coordination, the carbene behaves as a neutral $2 \mathrm{e}^{-}$ligand generating a formal double bond with the metal. The stability, reactivity and bonding properties greatly depend on the nature of the metal, the ligands on the metal and the substituents of the carbene fragment, whereby the metal carbene complexes have been divided into two main groups: ${ }^{1}$ Fischer-type carbenes (Figure 1, left), characterized by the interaction of a singlet carbene ligand with a metal fragment in the singlet state which leads to a significant carbene to metal $\sigma$ donation $\left(s p^{2} \rightarrow d\right)$ and a weaker metal to carbene $\pi$ back-donation $\left(d \rightarrow p_{z}\right)$ that renders the carbene carbon electrophilic; and Schrock-type carbenes or alkylidenes (Figure 1, right), derived from the combination of a triplet carbene and a triplet metal fragment leading to a "covalent-like" double bond which is polarized towards the carbene moiety, making it nucleophilic.

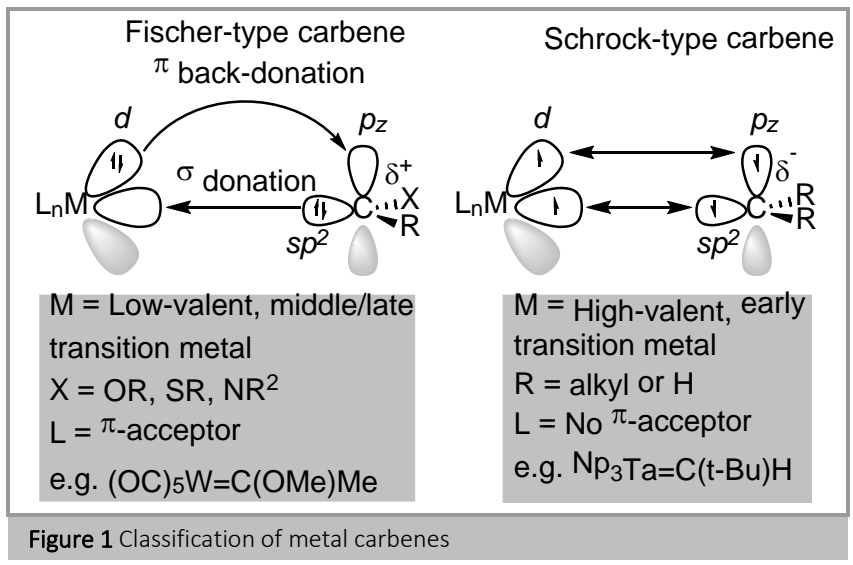

Since the synthesis, isolation and characterization of the first metal carbene complex, a tungsten carbonyl methoxymethylcarbene, by E. O. Fischer and A. Maasböl in $1964,{ }^{2}$ metal carbenes have been used in many catalytic processes $^{3}$ like alkene and enyne metathesis, ${ }^{4}$ alkyne polymerization, ${ }^{5}$ cyclopropenation, ${ }^{6}$ etc. In situ generated catalytic metal carbenes ${ }^{1 a, 3,7}$ have been invoked as intermediates for cycloadditions, insertions or skeletal rearrangements. ${ }^{8}$

Substitution in carbenes has a significant influence on their reactivity. When the substituent is a vinyl group, it is governed by the combination of three factors: i) the presence of a three carbon-four electron $\pi$-system; ii) the existence of two electrophilic positions ( $\alpha$ and $\gamma$ positions) and iii) the possible existence of two coordination modes ( $\eta 1$ or $\eta 3$ coordination) (Figure 2). Such features render metal vinyl carbenes valuable intermediates in organometallic chemistry with potential 
applications in organic synthesis. In this account, we will highlight the main synthetic applications involving catalytic processes through ruthenium vinyl carbene intermediates. ${ }^{9}$

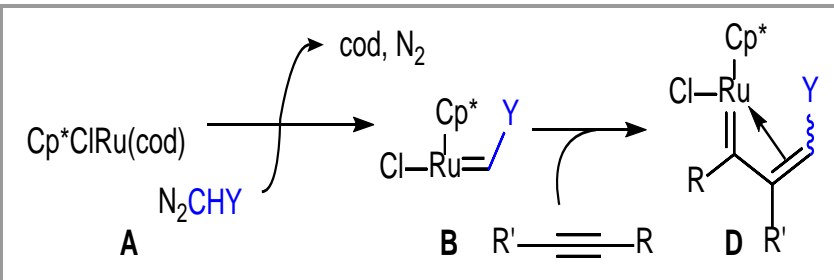

Figure 2 Characteristics of metal vinyl carbenes

\section{Ruthenium Vinyl Carbenes Through Carbene/Alkyne Metathesis (CAM)}

In a metal mediated carbene/alkyne metathesis (CAM), a carbene fragment from a metal complex migrates to an alkyne with the concomitant generation of a metal vinyl carbene where a new carbon-carbon double bond and a new metal carbene are being formed. ${ }^{10}$ Different mechanisms have been proposed for this process depending on the metal complex used and its oxidation state (Scheme 1). In the case of low-valent metals, such as $\operatorname{Co}(I)^{11}$ or $\operatorname{Ir}(I),{ }^{12}$ the metal carbene undergoes a $(2+2)$ cycloaddition with the alkyne to yield a metallacyclobutene intermediate which subsequently ring opens through a cycloreversion to give the metal vinyl carbene (Scheme 1, route A). Originally, this was considered the standard mechanism for CAM catalyzed by most transition metals; however, new experimental and theoretical data indicate that the mechanisms differ from one metal to another. Thus, cyclopropenes, formed through a concerted $(2+1)$ cycloaddition between metal carbenes and alkynes (Scheme 1, route B), ${ }^{13}$ or direct concerted reaction with alkynes to yield ruthenium vinyl carbenes (Scheme 1, route C) ${ }^{14}$ have been identified or postulated.

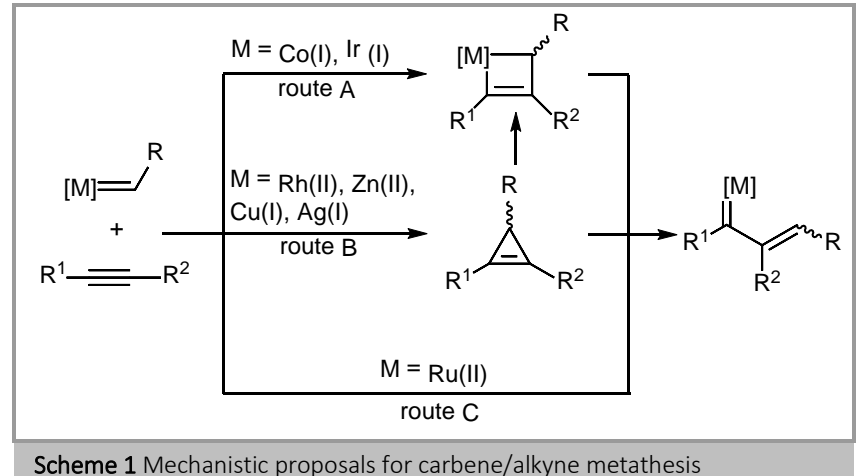

In 2000, Dixneuf and coworkers discovered a new methodology for the in situ generation of ruthenium vinyl carbenes by combining diazoalkanes and alkynes in the presence of catalytic amounts of $\mathrm{Cp} * \mathrm{RuCl}(\mathrm{cod})$ (Scheme 2). ${ }^{15}$ Catalytic ruthenium vinyl carbene intermediates have been invoked in a variety of transformations that will be presented in the next sections.

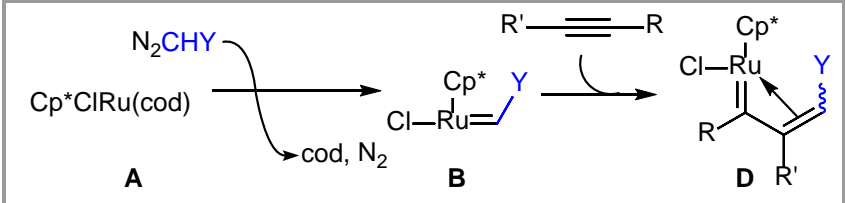

Scheme 2 Generation of ruthenium vinyl carbenes from $\mathrm{Cp} * \mathrm{RuCl}(\mathrm{cod})$, diazocompounds and alkynes

\section{Nonpolar Transformations of Ruthenium Vinyl Carbenes}

The reaction products formed via ruthenium vinyl carbene intermediates strongly depend on the nature of the alkyne.16 Thus, non-functionalized alkynes generate 1,3-dienes via double diazoalkane carbene addition to the triple bond. ${ }^{15,17}$ For example, reaction of mono- and disubstituted alkynes with two equivalents of trimethylsilyldiazometane in the presence of Cp*RuCl(cod) afford 1,4-bistrimethylsilylbuta-1,3-dienes through initial formation of ruthenium vinyl carbene I which interacts directly with a second unit of the diazocompound to afford the observed diene either directly or via the cis biscarbene II (Scheme 3).

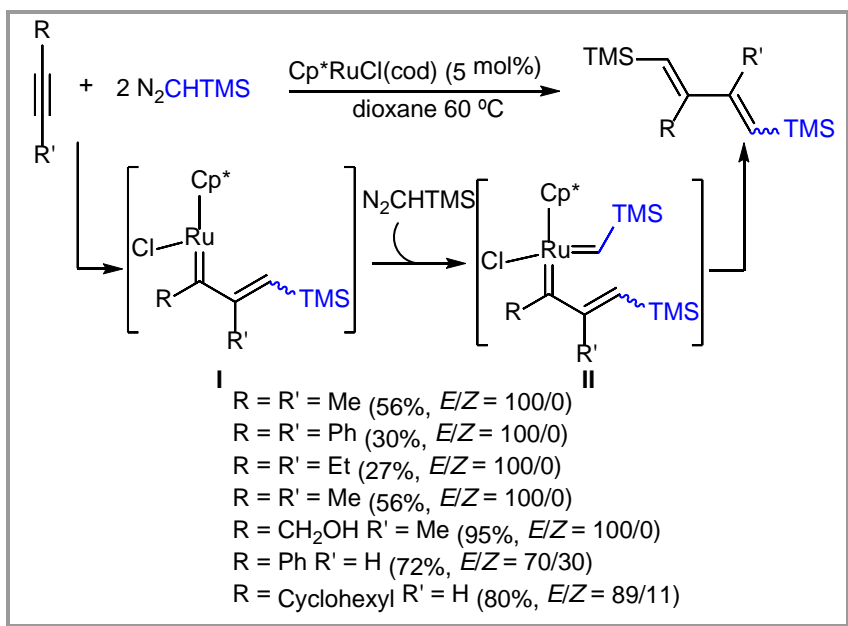

Scheme 3 1,3-Dienes by double diazoalkane carbene addition to alkynes catalyzed by $\mathrm{Cp} * \mathrm{RuCl}(\mathrm{cod})$

Functionalized 1,3-dienes could also be obtained by Rautenstrauch rearrangement of ruthenium vinyl carbenes I, generated in situ by reaction of propargylic carboxylates with diazoalkanes in the presence of catalytic $\mathrm{Cp}^{*} \mathrm{RuCl}(\mathrm{cod})$ (Scheme 4). ${ }^{18}$ 


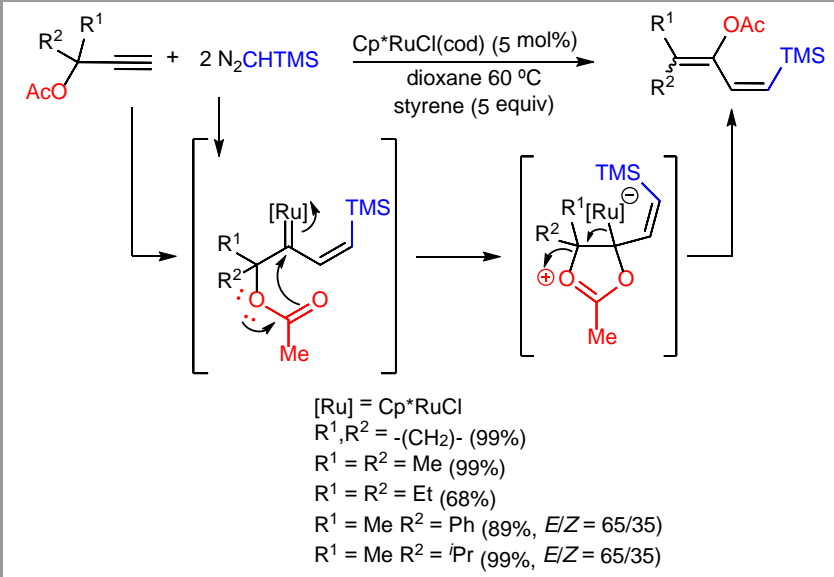

Scheme 4 Functionalized 1,3-dienes by Rautenstrauch rearrangement of ruthenium vinyl carbenes derived from diazoalkane, propargylic carboxylates and catalytic $\mathrm{Cp}{ }^{*} \mathrm{RuCl}(\mathrm{cod})$

Bicyclic [n.1.0] systems can also be achieved by using enynes in the presence of catalytic $\mathrm{Cp} * \mathrm{RuCl}(\mathrm{cod})$ and diazocompounds. Alkenyl bicyclo[3.1.0] hexanes and bicyclo[4.1.0]heptanes can be ensembled by $\mathrm{Cp} * \mathrm{RuCl}(\mathrm{cod})$ - catalyzed reaction between $\mathrm{C}$-, $\mathrm{N}$ - and 0-tethered 1,6- and 1,7-enynes and diazocompounds by initial formation of the corresponding ruthenium vinyl carbene through CAM followed by a concerted [2+1] reaction (cyclopropanation) of the carbene into de double bond of the alkene (Scheme 5). ${ }^{19}$ Remarkably, when electron-rich $\mathrm{N}_{2}$ CHTMS was used the major diastereoisomer obtained had $Z$ geometry, while with conjugated diazolkanes such as $\mathrm{N}_{2} \mathrm{CHCO}_{2} \mathrm{Et}$ and $\mathrm{N}_{2} \mathrm{CHPh}$ the major isomer presented $E$ geometry.

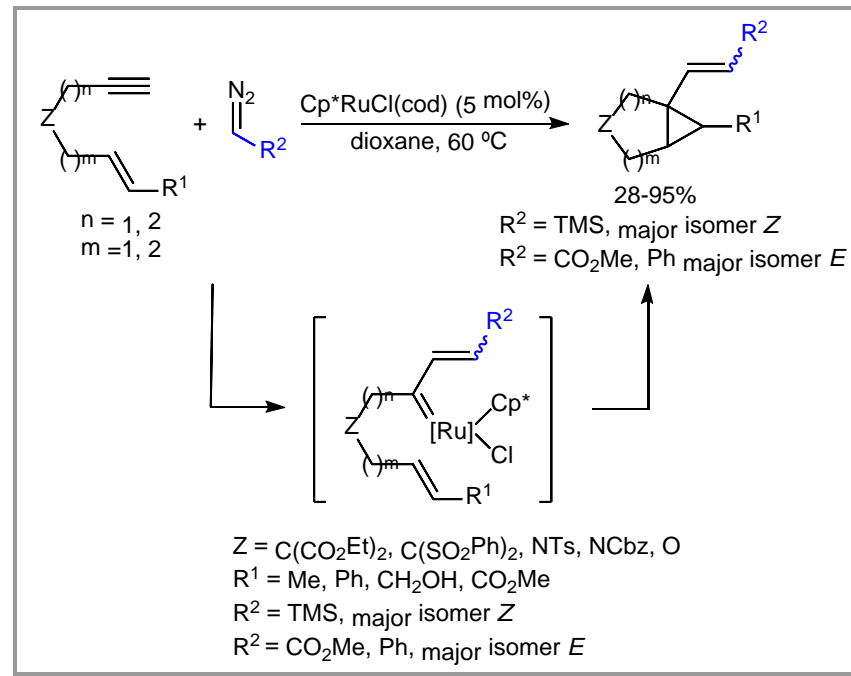

Scheme 5 Alkenyl bicyclic systems by $\mathrm{Cp} * \mathrm{RuCl}(\operatorname{cod})$-catalyzed reaction of 1,6and 1,7-enynes with diazocompounds

Enynes bearing a substituted triple bond or with a propargylic substitution disfavor the tandem CAM process. Thus, cyclopropanes $\mathbf{A}$ are formed by direct cyclopropanation of the alkene moiety when the alkyne bears bulky substituents (Scheme 6); $\alpha$-alkenyl alkylidene cyclopentanes B together with the expected alkenyl bicyclo[3.1.0] hexanes $\mathbf{C}$ are obtained when the enyne possess propargyl $\alpha, \alpha$-disubstitutions (Scheme 6). ${ }^{19 b}$

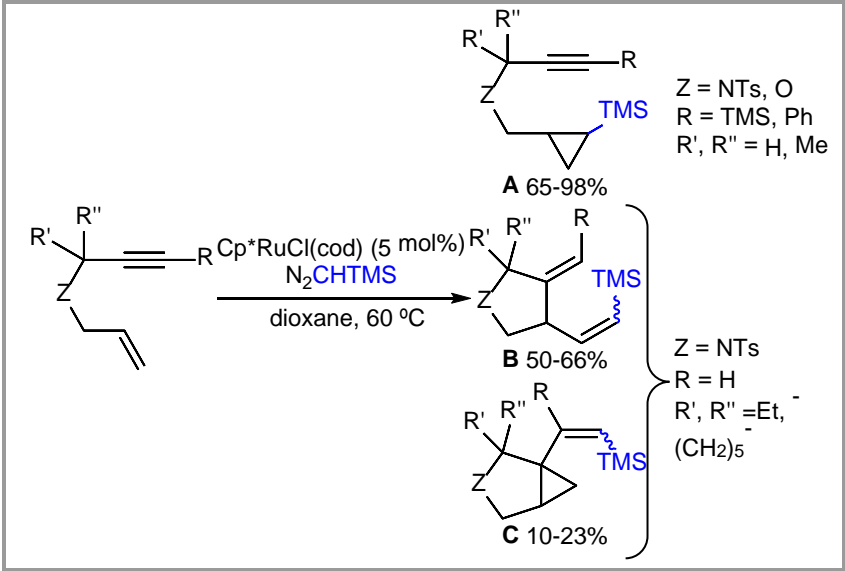

Scheme $6 \mathrm{Cp}$ *RuCl(cod)-catalyzed reaction of enynes bearing propargylic $\alpha, \alpha$-disubstituted and internal/terminal alkynes with $\mathrm{N}_{2} \mathrm{CHTMS}$

Similarly, alkenyl bicyclo[3.1.0]hexanes and bicyclo[4.1.0] heptanes are obtained from 1,6- and 1,7-enynes with alkenyl/allylic substituted substrates (Scheme 7). ${ }^{20}$

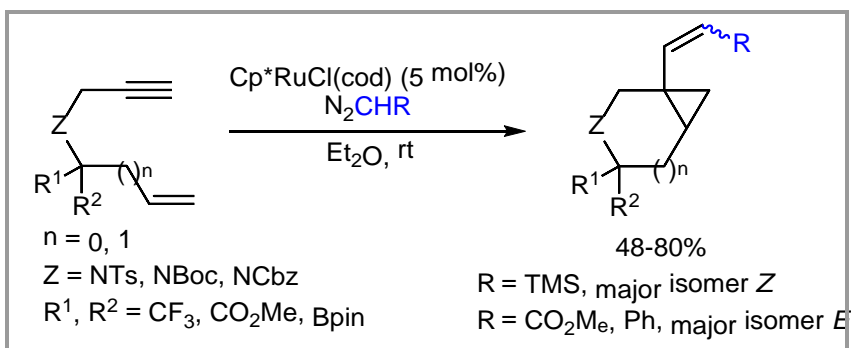

Scheme $7 \mathrm{Cp} * \mathrm{RuCl}(\mathrm{cod})$-catalyzed reaction of allylic substituted 1,6- and 1,7enynes with diazocompounds

Furthermore, allenynes reacted under the same catalytic conditions to afford alkylidenebicyclo[3.1.0] hexanes having and adjacent bridgehead-substituted (Z)-CH=CHTMS group (Scheme 8). ${ }^{21}$

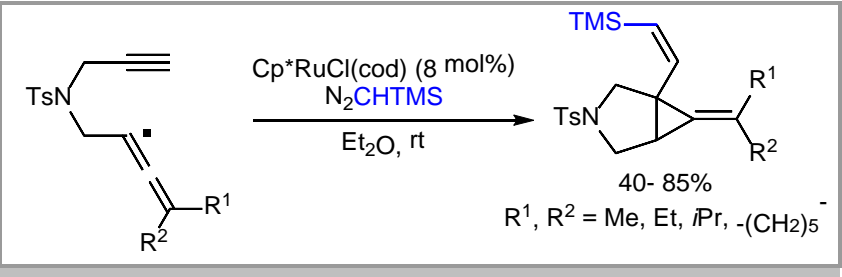

Scheme $8 \mathrm{Cp} *$ RuCl(cod)-catalyzed reaction of allenynes with $\mathrm{N}_{2} \mathrm{CHTMS}$

\section{Polar Transformations of Ruthenium Vinyl Carbenes}

A decade ago we initiate a program in our group to evaluate the reactivity as electrophile of the ruthenium vinyl carbene intermediates to be applied in polar transformations.

\subsection{Intramolecular Ruthenium Catalyzed [1,5]- and $[1,6]-H y d r i d e$ Transfer/Cyclization}

During the last few years, metal-catalyzed $\mathrm{C}-\mathrm{H}$ activation/functionalization has been positioned as a powerful tool for the step-economical construction of C-C and C- 
heteroatom bonds starting from hydrocarbons. ${ }^{22}$ While extensive methodology has been developed for the functionalization of Csp2-H bonds, Csp3-H bonds remain more challenging due to its high bond dissociation energy.

A selective activation and direct functionalization of $\mathrm{Csp}^{3}-\mathrm{H}$ bonds towards five- and six-membered carbo- and heterocycles has been devised by ruthenium-catalyzed redox, neutral [1,n]hydride transfer/cyclization processes. ${ }^{23}$ Ruthenium vinyl carbene intermediates derived from CAM reaction of trimethylsilyldiazomethane and alkynylacetals behave as hydride acceptors in intramolecular [1,n]-hydride transfers to afford functionalized carbo- and spirocycles. ${ }^{24}$ Tertiary $\mathrm{Csp}^{3}-\mathrm{H}$ of linear and cyclic acetal derivatives undergo [1,5] and [1,6]hydride transfer/cyclizations in moderate to good yields (Scheme 9).

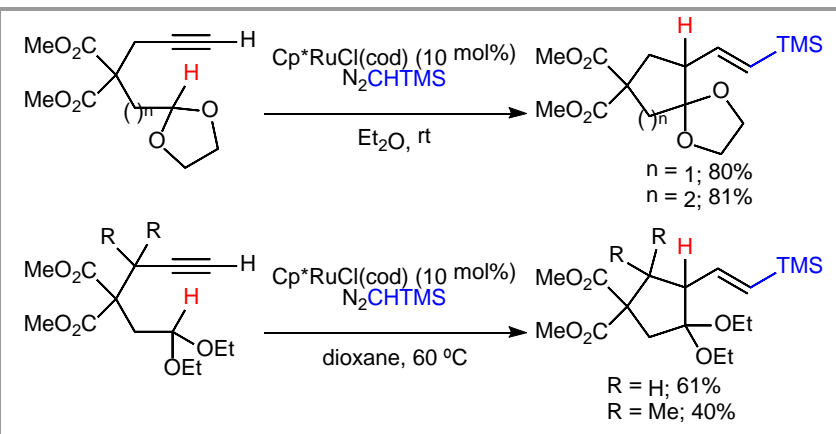

Scheme 9 Ruthenium-catalyzed [1,5]- an [1,6]-hydride transfer/cyclizations of tertiary Csp3-H of alkynylacetals

Even alkynyl tetrahydrofurans and pyrans $(X=0, n=1,2)$ and pyrrolidines $(X=N)$, having less activated tertiary Csp3-H by single heteroatoms, underwent $[1,5]$ and $[1,6]$-hydride transfer/cyclization processes to provide the bicyclic oxa- and azaspiranes in fairly good yields with high diastereoselectivities or as single diastereomer, respectively. Unfortunately, pure tertiary Csp3-H of cycloalkanes failed to react (Scheme 10).

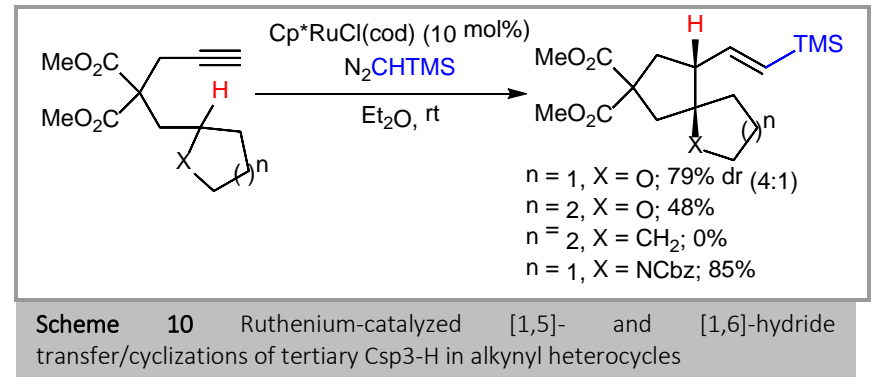

Moreover, secondary linear $\mathrm{Csp}^{3}-\mathrm{H}$ of alkynyl ethers also underwent [1,5]-hydride transfer/cyclization processes. Trans homoallylic ethers could be obtained from acyclic ethers and tetrahydrofurans in moderate to good yields (Scheme 11). Interestingly, activation of the secondary $\mathrm{Csp}^{3}-\mathrm{H}$ of piperidines gave a single diastereoisomer of the corresponding bicyclic derivative.

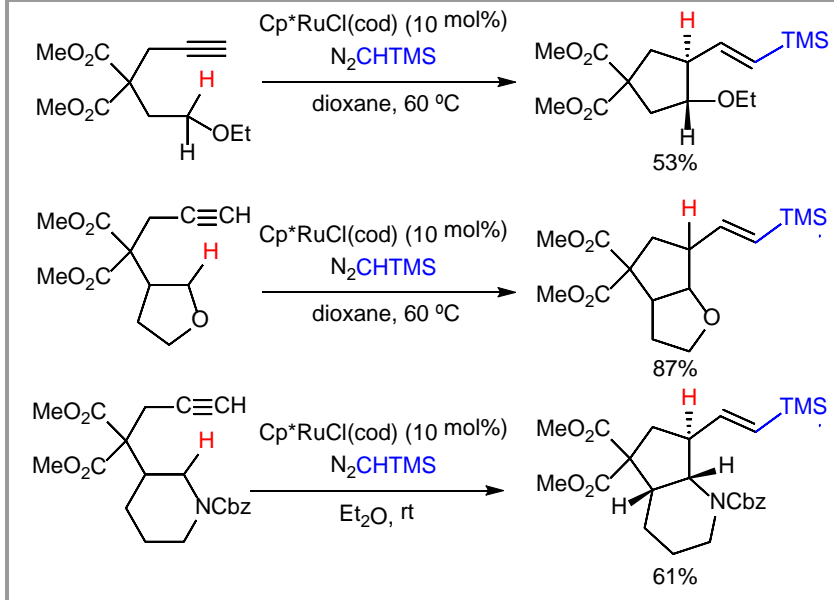

Scheme 11 Ruthenium-catalyzed [1,5]-hydride transfer/cyclization of secondary $\mathrm{Csp3}-\mathrm{H}$ in alkynyl ethers and heterocycles

The mechanistic hypothesis for the Ru-catalyzed [1,5]-hydride transfer/cyclization processes in cyclic alkynyl acetals is shown in Scheme 12. After initial formation of ruthenium carbene I, a CAM process arises to generate the vinyl ruthenium carbene II. Then, a [1,5]-hydride transfer assisted by the heteroatoms affords a transient zwitterionic species which is trapped to give the ruthenacycle III. ${ }^{14 a}$ A reductive elimination would finally afford the spiroacetal with recovery of the Ru(II) catalyst.

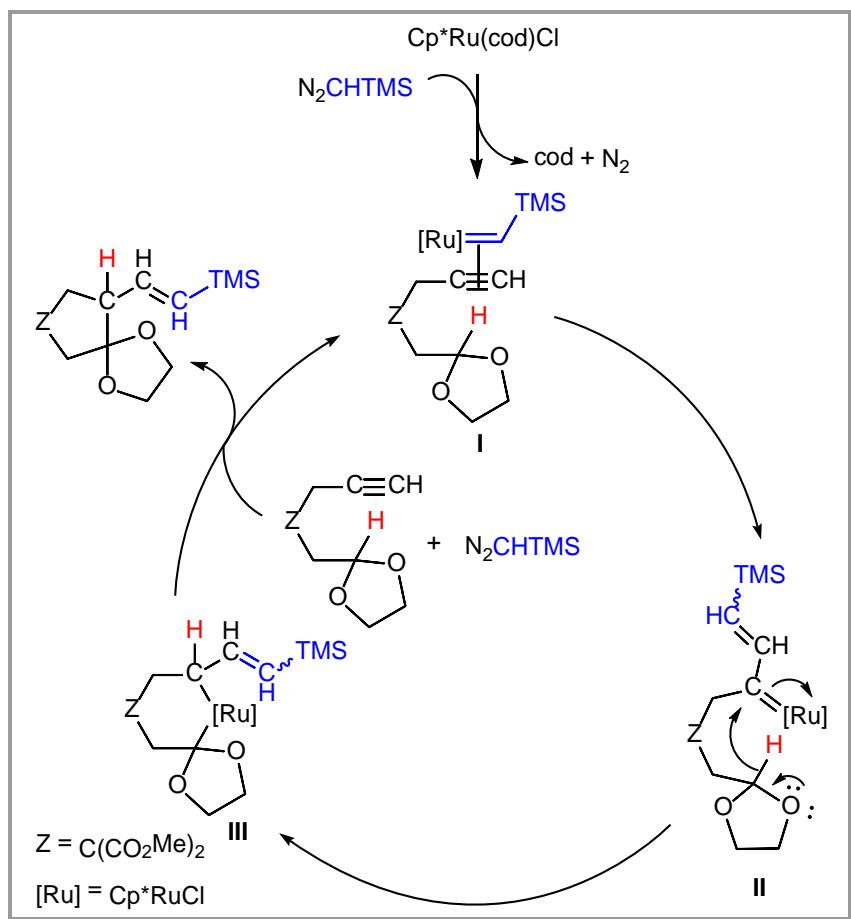

Scheme 12 Mechanistic hypothesis for the Ru-catalyzed [1,5]-hydride transfer/cyclization in cyclic alkynyl acetals

\subsection{Heterocyclizations of Alkynals and Alkynones}

Electrophilic vinyl ruthenium carbenes derived from $\mathrm{Cp}^{*} \mathrm{RuCl}(\mathrm{cod})$-catalyzed $\mathrm{CAM}$ reaction between alkynals/alkynones and trimethylsilyldiazomethane could be catched with 0-nucleophiles from the carbonyl functionalities to give five- and six-membered oxaheterocycles. ${ }^{25}$ 2-Vinyl-3,4- 
dihydropyrans were obtained in good yields and high diastereoselectivities starting from 3,3- and 3,3,4-substituted alkynals (Scheme 13).26

$$
\begin{aligned}
& { }_{\text {PrOH, rt }} \\
& \mathrm{N}_{2} \mathrm{CHTMS}
\end{aligned}
$$

Scheme 13 Ruthenium-catalyzed heterocyclization of di- and trisubstituted alkynals to 2-vinyl-3,4-dihydropyrans

With a glimpse to future applications to the synthesis of bioactive tetrahydropyrans, we undertook the reevaluation of the diastereoselectivity of the reaction with 3-monosubstituted alkynals. Alkynals bearing ester and ether functionalities afforded, to our delight, the corresponding 2-vinyl-3,4dihydropyrans as single cis diastereomers (Scheme 14). However, although alkynals bearing bulkier 3-silyloxy substituents were very well tolerated in terms of reactivity, they showed lower diastereoselectivities.

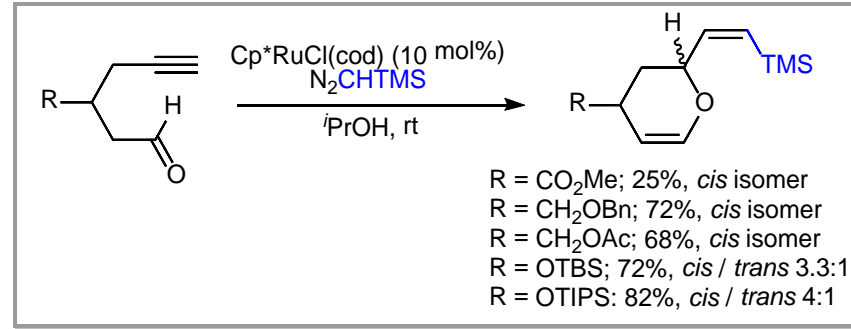

Scheme 14 Ruthenium-catalyzed heterocyclization of 3-alkynals to 2-vinyl3,4-dihydropyrans

Similarly, alkynones were also capable to undergo ruthenium catalyzed heterocyclizations to 6-substituted 2-vinyl-3,4dihydropyrans (Scheme 15). As before, 3-monosubstituted alkynones showed complete diastereoselectivity to give the cis 2,4,6-trisubstituted dihydropyrans, and also to the enantiomerically pure dihydropyrans if the starting alkynone was $(R)$ 3-(tert-butylsilyloxy)alkynones (Scheme 15).

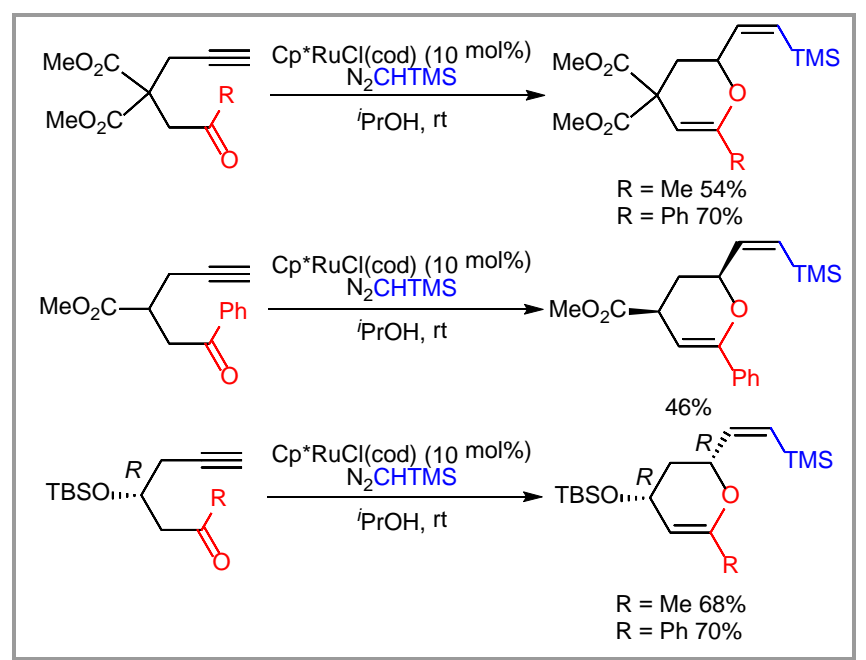

Scheme 15 Diastereo- and enantiomerically ruthenium-catalyzed

\section{heterocyclization of alkynones to 6-substituted 2-vinyl-3,4-dihydropyrans}

Optically active 2,3-dihydrofurans, which are synthetically relevant structures for a plethora of natural and bioactive products, ${ }^{27}$ can be easily accessed via Ru-catalyzed heterocyclization of (2S,3R)-1,4-alkynones derived from enantioselective propargylic alkylation of acyclic ketone enamines (Scheme 16). ${ }^{28}$

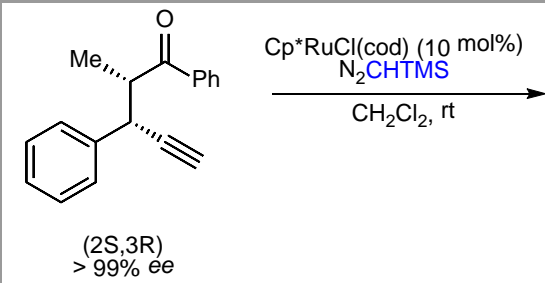<smiles>CC1=C(c2ccccc2)O[C@@H](/C=C\C(C)(C)C)[C@@H]1c1ccccc1</smiles>

$79 \%$ yield $>96 / 5 \mathrm{dr},>99 \%$ ee
Scheme 16 Ruthenium-catalyzed heterocyclization of (2S,3R)-1,4-alkynones to active 2,3-dihydrofurans

The tentative mechanism for the Ru-catalyzed heterocyclization of alkynals and alkynones to give 2-vinyl-3,4-dihydropyrans is shown in Scheme 17. After initial generation of the electrophilic vinyl ruthenium carbene II through CAM reaction, a nucleophilic attack of the carbonyl would afford the zwitterionic intermediate III. The diastereoselectivity seems to be controlled on the nucleophilic attack of the carbonyl through the more stable chair-like conformer of carbene IIa with all the equatorial substituents. Final deprotonation and reductive elimination would give rise to the observed dihydropyran with regeneration of the active ruthenium species for the next catalytic cycle.

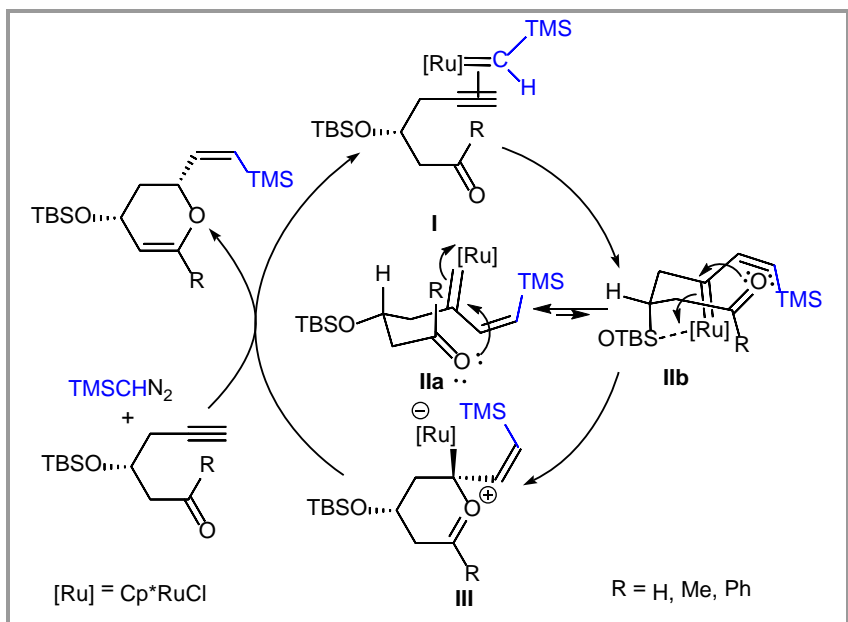

Scheme 17 Mechanistic hypothesis for the ruthenium-catalyzed heterocyclization of alkynal and alkynones

Likewise, $N$-tethered alkynals (aza-alkynals) and alkynones also underwent heterocyclizations to give the corresponding 2vinyl-3,4-dihydro-2H-1,4-oxazines in moderate to good yields (Scheme 18). 


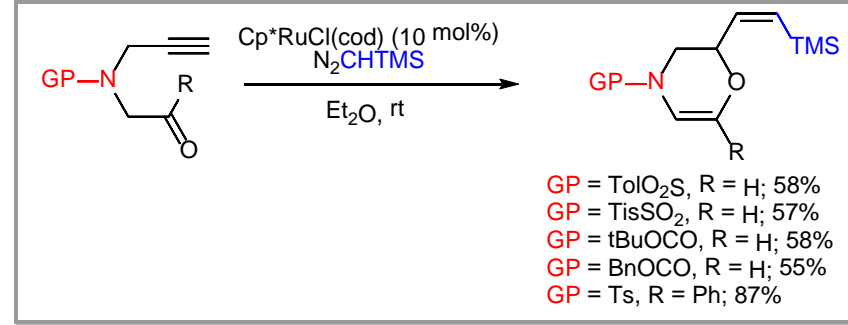

Scheme 18 Ruthenium-catalyzed heterocyclizations of $N$-tethered alkynals and alkynones to 2-vinyl oxazine derivatives

Remarkably, 2,2-disubstituted aza-alkynals undergo a divergent cyclization reaction leading to vinyl epoxypyrrolidines $(\mathrm{n}=0)$ and epoxypiperidines $(n=1)$, valuable building blocks for the synthesis of bioactive compounds (Scheme 19). ${ }^{29}$

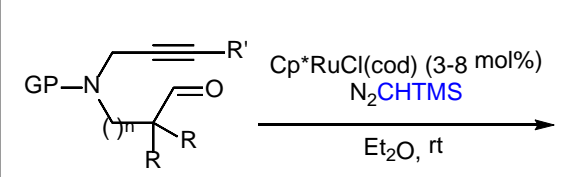

$$
\begin{aligned}
& \mathrm{n}=0,1 \\
& \mathrm{PG}=\mathrm{Ts}, \mathrm{Ms}, \mathrm{Ns}, \mathrm{Cbz}
\end{aligned}
$$

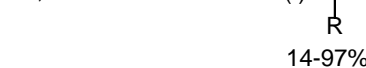

$$
\begin{aligned}
& \mathrm{R}=\mathrm{Me},-\left(\mathrm{CH}_{2}\right) 3^{-},-\left(\mathrm{CH}_{2}\right) 4^{-},-\left(\mathrm{CH}_{2}\right) 5^{-} \\
& \mathrm{R}^{\prime}=\mathrm{H}, \mathrm{Me}
\end{aligned}
$$

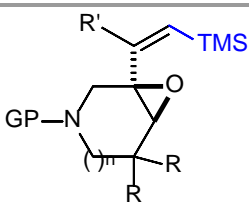

Scheme $19 \mathrm{Cp} * \mathrm{Ru}(\mathrm{cod})$-catalyzed cyclization of $\alpha, \alpha^{\prime}$-disubstituted azaalkynals and trimethylsilyldiazomethane to epoxypyrrolidines and epoxypiperidines

When conjugated diazoalkanes were used, the reaction also occurred but, interestingly, the geometry of the vinyl substituent changed to $E$ instead of the $Z$ observed when $\mathrm{TMSCHN}_{2}$ was used (Scheme 20).

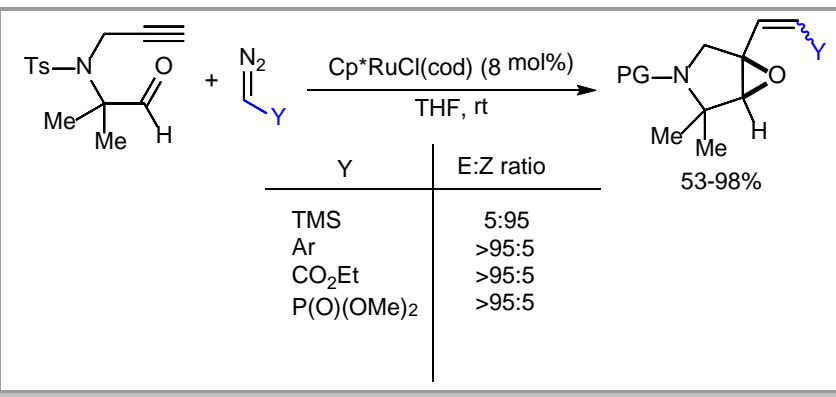

Scheme $20 \mathrm{Cp} * \mathrm{Ru}(\mathrm{cod})$-catalyzed cyclizations of $\alpha, \alpha^{\prime}$-disubstituted azaalkynals and diazoalkanes to vinyl epoxypyrrolidines.

Interestingly, $\alpha$-monosubstituted aza-alkynals reacted chemoand diastereoselectively to give the corresponding epoxypyrrolidines in moderate yields (Scheme 21).

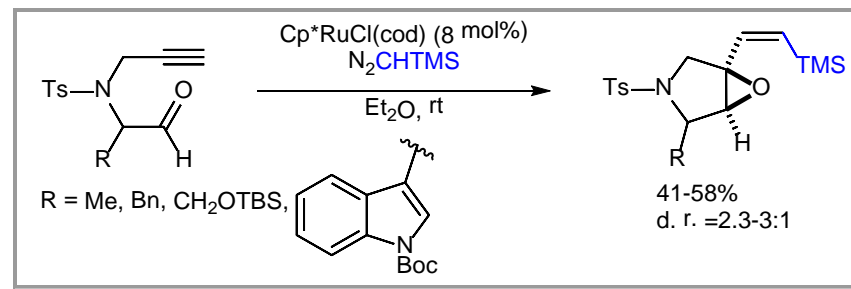

Scheme 21 Chemo- and diastereoselective formation of epoxypyrrolidines by $\mathrm{Cp} * \mathrm{Ru}(\mathrm{cod})$-catalyzed cyclization of $\alpha$-monosubstituted alkynals and trimethylsilyldiazomethane

The mechanistic hypothesis for the $\mathrm{Cp}^{*} \mathrm{RuCl}(\operatorname{cod})$-catalyzed epoxyannulation is shown in Scheme 22. The initially formed alkynal-carbene complex I would evolve through CAM to the electrophilic vinyl ruthenium carbene intermediate II. A subsequent nucleophilic attack by the carbonyl group gives rise to the oxonium species III, which finally ends up in the observed epoxypyrrolidine. In this particular case, the lack of hydrogens (or sterically hindered) at $\alpha$ position preclude or highly hamper the deprotonation/reprotonation step blocking the formation of dihydrooxazine. Evolution of the vinyl carbene II via a formal [2+2] cycloaddition to the oxaruthenacycle III' and final reductive elimination cannot be excluded.

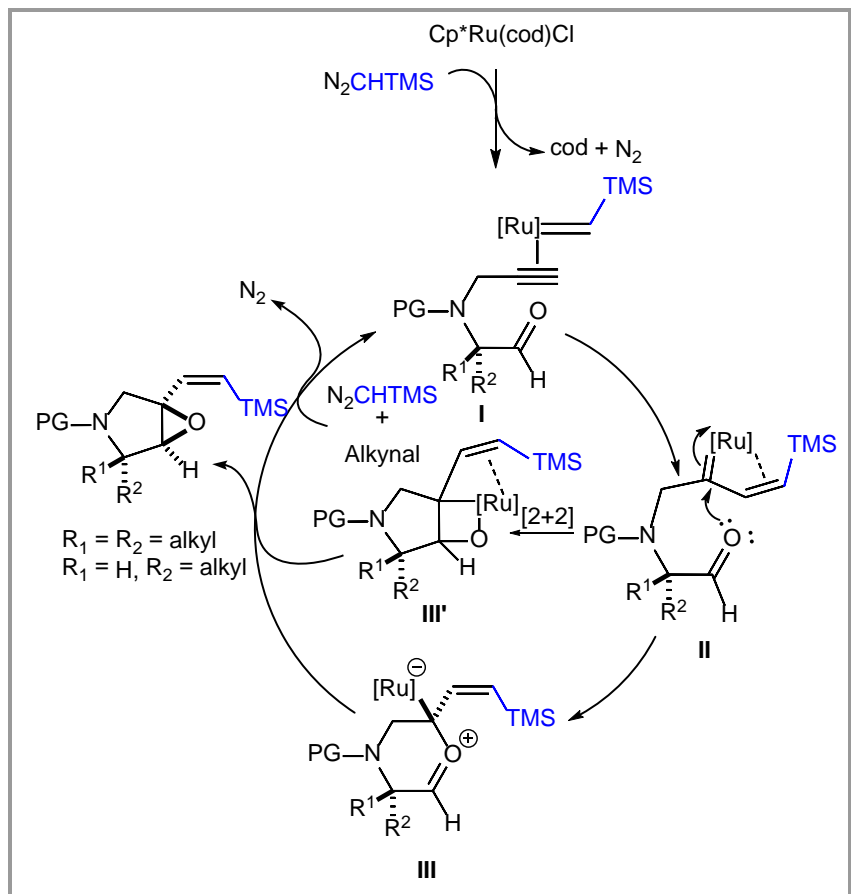

Scheme 22 Mechanistic hypothesis for the Cp*RuCl(cod)-catalyzed epoxyannulation of alkynals with trimethylsilyldiazomethane

\section{3}

Heterocyclizations
(Alkynyloxy)benzylamines

of

ortho-

Electrophilic ruthenium vinyl carbenes from $\mathrm{Cp}^{*} \mathrm{RuCl}(\mathrm{cod})$ catalyzed CAM reaction between $\omega$-alkynyl benzylamines and trimethylsilyldiazomethane could also be catch by $\mathrm{N}$ nucleophiles of benzylamine derivatives. ${ }^{30}$ Thus, rutheniumcatalyzed heterocyclization of $o$-(alkynyloxy)benzylamines afforded 2,2-disubstituted dihydro-1,3-benzoxazines, presumably by a nucleophilic attack of the amine to the ruthenium vinyl carbene followed by a sequential ring opening/ring closure rearrangement (Scheme 23). ${ }^{31}$

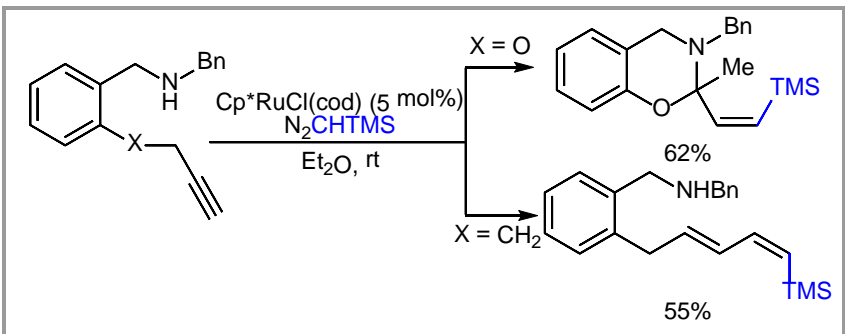

Scheme 23 Ruthenium-catalyzed reactions of C- and O-tethered oalkynylbenzylamines 
Substitution on the aromatic ring of benzylamines is well tolerated for these processes (Scheme 24). Both electron-rich and electron-poor aromatic rings are reactive enough to give the corresponding 1,3-benzoxazines in relatively good yields, a bit better for the electron-poor rings. Halo-1,3-benzoxazines are easily accessible except the sterically hindered ortho-bromo 1,3benzoxazine, which might outlook future manipulations of these substrates.

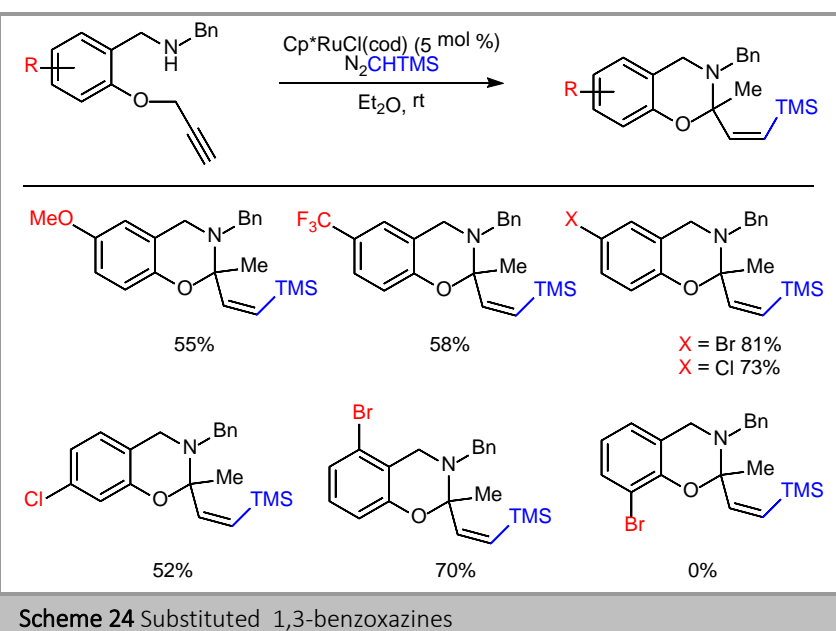

Alkynyl substituted substrates also cyclized to give the corresponding 1,3-benzoxazines in moderate to good yields, although longer times and heating conditions are needed (Scheme 25, eq 1). On the other hand, primary and secondary benzylamines are also accepted affording the corresponding 1,3-benzoxazines in good yields. Polar interactions seem to control the reactivity of the carbene intermediate since $\mathrm{N}$-allyl substituent on benzylamine remains intact during the reaction (Scheme 25, eq 2). Propargyl substituted alkynylamines are also well tolerated. Methyl monosubstituted and methyl disubstituted propargylic benzylamines gave rise to the rearranged 2-ethyl and 2-isopropyl substituted 1,3benzoxazines in low to moderate yields. (Scheme 25, eq 3).

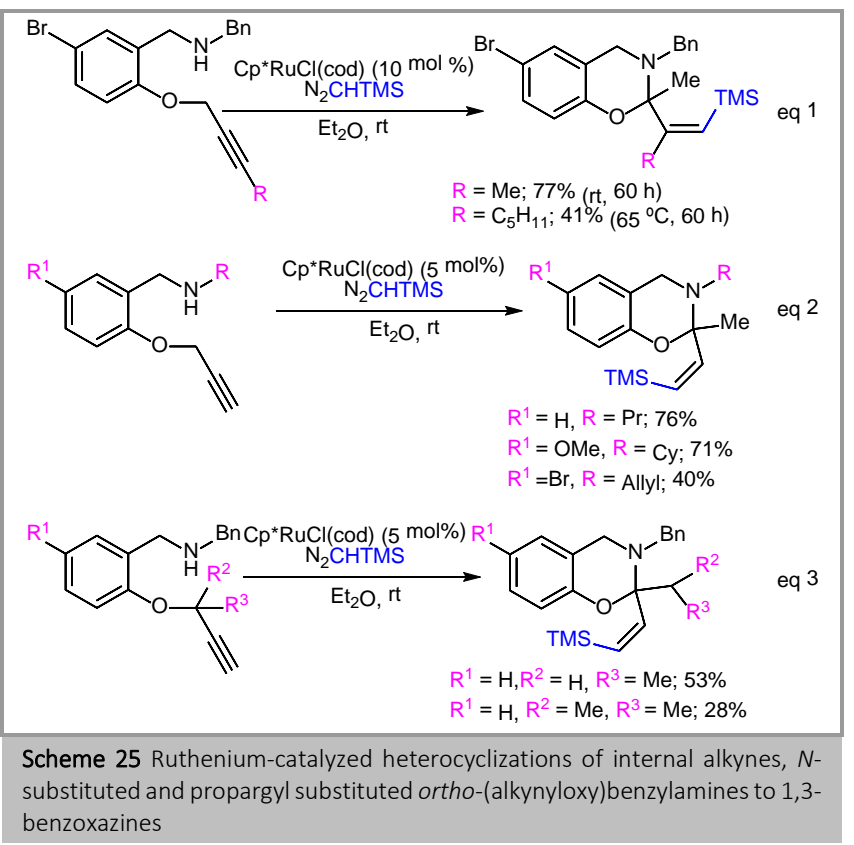

The proposed mechanism involves an initial formation of the alkynylamine-carbene complex I that would evolve through CAM to the electrophilic vinyl ruthenium carbene intermediate II. Saturation of ruthenium to give the $18 \mathrm{e}^{-}$complex by nitrogen coordination might be occurring. Then, a subsequent nucleophilic attack to the carbene would afford the zwitterionic species III that ring opens to a transient enamine IV. The acidic phenol would promote the final ring closing to afford the 2,2disubstituted 1,3-benzoxazine (Scheme 26).

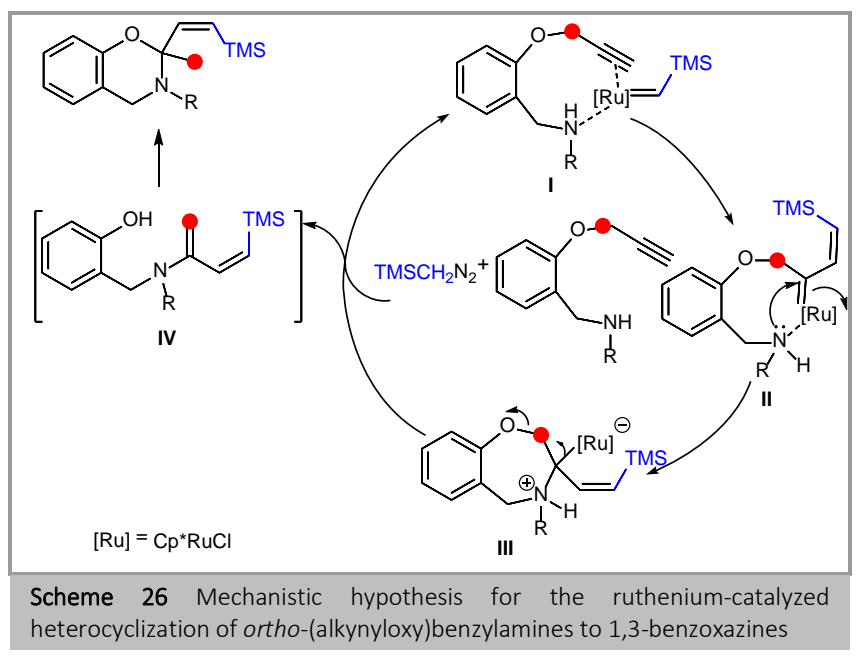

\section{DFT Studies on the Stereoselectivity of the CAM Reaction}

In all the nonpolar and the majority of polar transformations, the geometry of the double bond (stereoselectivity) of the ruthenium vinyl carbene intermediates through CAM reactions between trimethylsilyldiazomethane and alkynes and also in the final product is $Z$ except for the polar [1,n]-hydride transfer/cyclization which was found $E$. Nevertheless, with conjugated diazoalkanes such as $\mathrm{N}_{2} \mathrm{CHCO}_{2} \mathrm{Me}$ or $\mathrm{N}_{2} \mathrm{CHPh}$, the geometry of the final product is $E$ regardless of the type of transformation. A first premise to explain the stereoselectivity derives from the assumption of the vinyl ruthenium carbene formation during the electrocyclic opening of ruthenacyclobutene (Scheme 27), in which the $\mathrm{Cp}^{*}$ and $\mathrm{R}$ groups should be anti to minimize detrimental steric interactions. If $\mathrm{R}=$ $\mathrm{SiMe}_{3}$, intense attractive interactions should be operative between $\mathrm{SiMe}_{3}$ and $\mathrm{Cl}$ groups compelling a favourable $Z$ configuration after ring-opening. Conversely, if $\mathrm{R} \neq \mathrm{SiMe} 3$ steric hindrance should be the boost for the torquoselectivity delivering favourable $E$-configuration of the double bond (Scheme 27) ${ }^{15}$ 


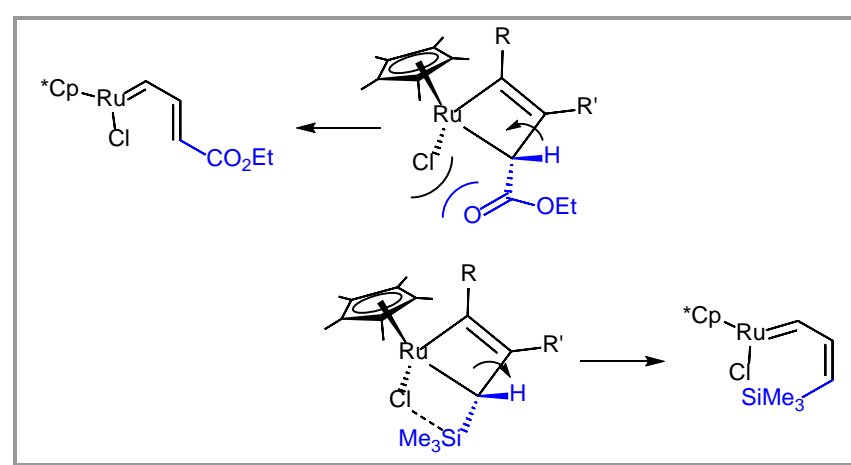

Scheme 27 Early hypothesis for the formation of Z- and E-vinyl ruthenium carbenes by ring-opening of ruthenacyclobutenes
To explain the appearance of the $E$ geometry and to clarify properly these early premises for the formation of ruthenium vinyl carbenes, DFT calculations were performed for the [1,n]hydride transfer/cyclization (Scheme 28). ${ }^{14 a}$ Three conformers in equilibria for the initial ruthenium carbene coordinated to the alkyne were observed: a) the conformer $\mathbf{A}$, with the hydrogen pointing to the $\mathrm{Cp}^{*}$ ring, being the more stable and b) the conformers $\mathbf{B}$ and $\mathbf{C}$, with the TMS group pointing to the $\mathrm{Cp}^{*}$ ring backwards and forward, respectively, being less stable.

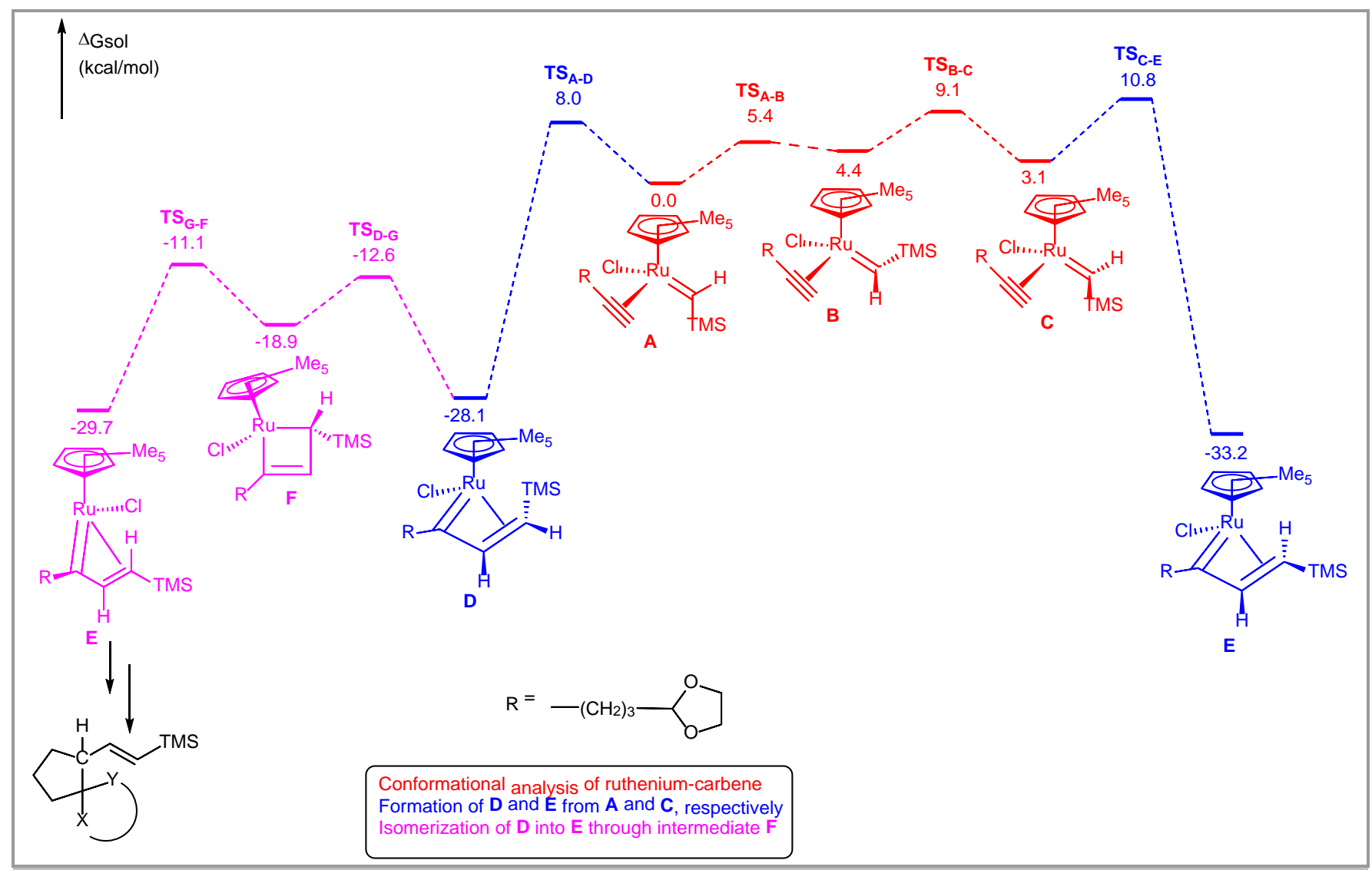

Scheme 28 Calculated potential free energy curve for the conformational equilibrium of alkyne coordinated $\mathrm{Cp} * \mathrm{RuCl}$ carbene and its transformation into $Z$ and $E$ vinyl ruthenium carbenes $\mathrm{D}$ and $\mathrm{E}$

Evolution either to the $Z$ - or $E$ - ruthenium vinyl carbenes $\mathbf{D}$ and $\mathbf{E}$ is favored to the $Z$ isomer $\mathbf{D}$ since the transition state is lower by $2.8 \mathrm{Kcal} \mathrm{mol}^{-1}$. The most favorable pathway involved the initial isomerization of $Z$ isomer $\mathbf{D}$ to the $E$ isomer $\mathbf{E}$ through ruthenacyclobutene intermediate $\mathbf{F}$, which could justify the $E$ geometry of the vinyl substituents found in the final products.

In the case of the other polar transformations, the most favorable pathway would start from intermediates of type D without isomerization, which would explain the appearance of the final products with $Z$ geometry.

To explain the observed $E$ stereoselectivity when conjugated diazoalkanes were used, DFT calculations for the transformation from alkyne-carbene complexes $\mathbf{A}^{\prime}$ to $Z$ - and $E$ ruthenium vinyl carbenes $\mathbf{D}^{\prime}$ and $\mathbf{E}^{\prime}$, respectively, were performed (Scheme 29). ${ }^{29}$ 


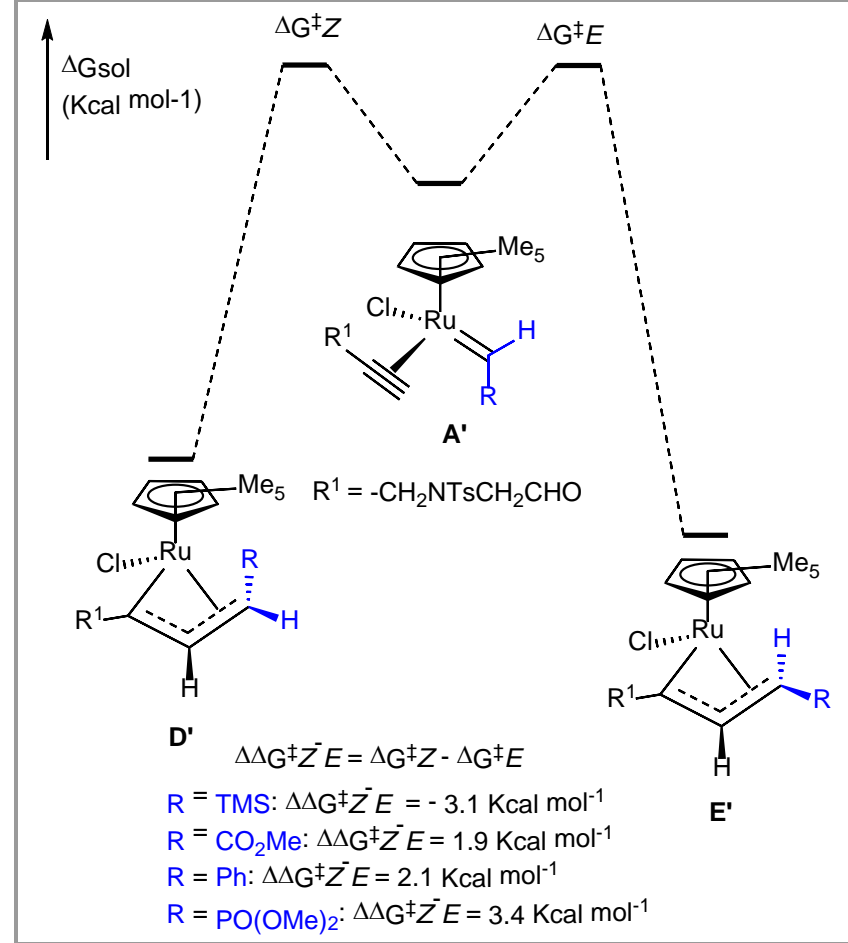

Scheme 29 Calculated potential free energy curve for the generation of $Z$ and $E$ - vinyl ruthenium carbenes by CAM reaction of several $C p^{*} R u C$ carbenes

From the results, trimethylsilyldiazomethane favor the formation of Z-vinyl ruthenium D' carbenes by $3.1 \mathrm{Kcal} \mathrm{mol}^{-1}$, while conjugated diazoalkanes favor the formation of $E$-vinyl ruthenium carbenes $\mathbf{E}^{\prime}$ (from $1.9 \mathrm{Kcal} \mathrm{mol}^{-1}$ for the $\mathrm{CO}_{2} \mathrm{Me}$ to 3.4 Kcal $\mathrm{mol}^{-1}$ for the $\left.\mathrm{PO}(\mathrm{OMe})_{2}\right)$. This stereochemical divergence might be attributed to the strong steric repulsion between the $\mathrm{Cp} *$ ligand and the bulky TMS group.

\section{Conclusions}

Recent advances in Ru-catalyzed synthetic applications involving carbene/alkyne metathesis (CAM) processes have been compiled. From the model schemes of this account, we can see the significant progress that has been accomplished in recent years. With the easy availability of ruthenium catalysts and the mild conditions needed, the use of CAM reactions for the development of new synthetic approaches is highly appealing. New challenges may focus on the preparation of structurally well-defined ruthenium vinyl carbenes as catalysts for the development of selective reactions, and also in the isolation and characterization of reactive $\mathrm{Ru}$ intermediates for a complete elucidation of reaction mechanism, which may provide insight for the design of new organic transformations. The development of chiral Ru vinyl carbene complexes for enantioselective transformations could be another interesting future task.

\section{Funding Information}

This work has received financial support from MINECO (project CTQ2017-87939R and ORFEO-CINQA network RED2018-102387-T), the Xunta de Galicia (project ED431C 2018/04 and Centro singular de investigación de Galicia accreditation 2019-2022, ED431G 2019/03) and the European Union (European Regional Development Fund - ERDF).

\section{Acknowledgment}

D. P. thanks MEC for a predoctoral FPU fellowship (FPU15/02132). We are also grateful to the CESGA (Xunta de Galicia) for computational time.

\section{References}

(1) (a) Dörwald, F. Z., The Carbon-Metal Double Bond. In Metal Carbenes in Organic Synthesis, 1998; pp 1. (b) Strassner, T., Electronic Structure and Reactivity of Metal Carbenes. In Metal Carbenes in Organic Synthesis, Springer Berlin Heidelberg: Berlin, Heidelberg, 2004; pp 1. (c) Tonzetich, Z. J., Nucleophilic Carbenes of the Chromium Triad. In Contemporary Carbene Chemistry, 2013; pp 452.

(2) Fischer, E. O.; Maasböl, A. Angew. Chem., Int. Ed. Engl. 1964, 3, 580.

(3) Moss, R. A.; Doyle, M. P., Contemporary Carbene Chemistry. ed.; John Wiley \& Sons, Inc.: Hoboken, 2014; p 566 pp.

(4) (a) Hoveyda, A. H.; Malcolmson, S. J.; Meek, S. J.; Zhugralin, A. R. Angew. Chem. Int. Ed. 2010, 49, 34. (b) Kotha, S.; Dipak, M. K. Tetrahedron 2012, 68, 397. (c) Fuerstner, A. Science 2013, 341, 1357. (d) Vougioukalakis, G. C.; Grubbs, R. H. Chem. Rev. 2010, 110, 1746. (e) Connon, S. J.; Blechert, S. Angew. Chem. Int. Ed. 2003, 42, 1900. (f) Nolan, S. P.; Clavier, H. Chem. Soc. Rev. 2010, 39, 3305. (g) Kress, S.; Blechert, S. Chem. Soc. Rev. 2012, 41, 4389. (h) Grubbs, R. H. Tetrahedron 2004, 60, 7117. (i) Diver, S. T.; Giessert, A. J. Chem. Rev. 2004, 104, 1317. (j) Katz, T. J. Angew. Chem. Int. Ed. 2005, 44, 3010. (k) Li, J.; Lee, D. Eur. J. Org. Chem. 2011, 2011, 4269. (l) Diver, S. T. Coord. Chem. Rev. 2007, 251, 671.

(5) (a) Masuda, T.; Higashimura, T. Acc. Chem. Res. 1984, 17, 51. (b) Katz, T. J.; Sivavec, T. M. J. Am. Chem. Soc. 1985, 107, 737. (c) Fox, H. H.; Wolf, M. O.; O'Dell, R.; Lin, B. L.; Schrock, R. R.; Wrighton, M. S. J. Am. Chem. Soc. 1994, 116, 2827.

(6) Rubin, M.; Rubina, M.; Gevorgyan, V. Chem. Rev. 2007, 107, 3117.

(7) Doyle, M. P.; McKervey, M. A.; Ye, T., Modern Catalytic Methods for Organic Synthesis with Diazo Compounds: From Cyclopropanes to Ylides. ed.; Wiley: New York, 1998; p 652 pp.

(8) (a) DeAngelis, A.; Panish, R.; Fox, J. M. Acc. Chem. Res. 2016, 49, 115. (b) Qian, D.; Zhang, J. Chem. Soc. Rev. 2015, 44, 677. (c) Archambeau, A.; Miege, F.; Meyer, C.; Cossy, J. Acc. Chem. Res. 2015, 48, 1021. (d) Wei, F.; Song, C.; Ma, Y.; Zhou, L.; Tung, C.H.; Xu, Z. Sci. Bull. 2015, 60, 1479. (e) Xia, Y.; Zhang, Y.; Wang, J. ACS Catal. 2013, 3, 2586. (f) Dorel, R.; Echavarren, A. M. J. Org. Chem. 2015, 80, 7321. (g) Hu, F.; Xia, Y.; Ma, C.; Zhang, Y.; Wang, J. Chem. Commun. 2015, 51, 7986. (h) Ford, A.; Miel, H.; Ring, A.; Slattery, C. N.; Maguire, A. R.; McKervey, M. A. Chem. Rev. 2015, 115, 9981.

(9) Dey, S.; De Sarkar, S. Adv. Synth. Catal. 2017, 359, 2709.

(10) Pei, C.; Zhang, C.; Qian, Y.; Xu, X. Org. Biomol. Chem. 2018, $16,8677$.

(11) (a) O'Connor, J. M.; Ji, H.; Iranpour, M.; Rheingold, A. L. J. Am. Chem. Soc. 1993, 115, 1586. (b) O'Connor, J. M.; Baldridge, K. K.; Vélez, C. L.; Rheingold, A. L.; Moore, C. E. J. Am. Chem. Soc. 2013, 135, 8826. (c) Holland, R. L.; Bunker, K. D.; Chen, C. H.; DiPasquale, A. G.; Rheingold, A. L.; Baldridge, K. K.; O'Connor, J. M. J. Am. Chem. Soc. 2008, 130, 10093.

(12) Li, R. T.; Nguyen, S. T.; Grubbs, R. H.; Ziller, J. W. J. Am. Chem. Soc. 1994, 116, 10032. 
(13) Nowlan, D. T.; Singleton, D. A. J. Am. Chem. Soc. 2005, 127, 6190.

(14) (a) Cambeiro, F.; Martínez-Núñez, E.; Varela, J. A.; Saá, C. ACS Catal. 2015, 5, 6255. (b) Lippstreu, J. J.; Straub, B. F. J. Am. Chem. Soc. 2005, 127, 7444.

(15) Le Paih, J.; Derien, S.; Oezdemir, I.; Dixneuf, P. H. J. Am. Chem. Soc. 2000, 122, 7400.

(16) Vovard-Le Bray, C.; Derien, S.; Dixneuf, P. H. C. R. Chim. 2010, 13, 292.

(17) Le Paih, J.; Vovard-Le Bray, C.; Derien, S.; Dixneuf, P. H. J. Am. Chem. Soc. 2010, 132, 7391.

(18) Vovard-Le Bray, C.; Derien, S.; Dixneuf, P. H. Angew. Chem. Int. Ed. 2009, 48, 1439.

(19) (a) Monnier, F.; Castillo, D.; Derien, S.; Toupet, L.; Dixneuf, P. H. Angew. Chem. Int. Ed. 2003, 42, 5474. (b) Monnier, F.; Vovard-Le Bray, C.; Castillo, D.; Aubert, V.; Derien, S.; Dixneuf, P. H.; Toupet, L.; Ienco, A.; Mealli, C. J. Am. Chem. Soc. 2007, 129, 6037.

(20) (a) Bray, C. V.-L.; Klein, H.; Dixneuf, P. H.; Macé, A.; Berrée, F.; Carboni, B.; Dérien, S. Adv. Synth. Catal. 2012, 354, 1919.

(b) Eckert, M.; Monnier, F.; Shchetnikov, G. T.; Titanyuk, I. D.; Osipov, S. N.; Toupet, L.; Derien, S.; Dixneuf, P. H. Org. Lett. 2005, 7, 3741. (c) Eckert, M.; Moulin, S.; Monnier, F.; Titanyuk, I. D.; Osipov, S. N.; Roisnel, T.; Dérien, S.; Dixneuf, P. H. Chem. Eur. J. 2011, 17, 9456.

(21) Vovard-Le Bray, C.; Derien, S.; Dixneuf, P. H.; Murakami, M. Synlett 2008, 193.

(22) (a) Godula, K.; Sames, D. Science 2006, 312, 67. (b) Girard, S. A.; Knauber, T.; Li, C.-J. Angew. Chem. Int. Ed. 2014, 53, 74. (c) Bergman, R. G. Nature 2007, 446, 391. (d) Chen, X.; Engle, K. M.; Wang, D.-H.; Yu, J.-Q. Angew. Chem. Int. Ed. 2009, 48, 5094. (e) Rouquet, G.; Chatani, N. Angew. Chem. Int. Ed. 2013, 52, 11726. (f) Jazzar, R.; Hitce, J.; Renaudat, A.; SofackKreutzer, J.; Baudoin, O. Chem. Eur. J. 2010, 16, 2654.

(23) (a) Wang, L.; Xiao, J. Adv. Synth. Catal. 2014, 356, 1137. (b) Haibach, M. C.; Seidel, D. Angew. Chem. Int. Ed. 2014, 53, 5010.

(24) Cambeiro, F.; López, S.; Varela, J. A.; Saá, C. Angew. Chem. Int. Ed. 2012, 51, 723.

(25) Alkynols do not undergo CAM processes since the diazocompound is inmmediately trapped with the hydroxyl group.

(26) Cambeiro, F.; López, S.; Varela, J. A.; Saá, C. Angew. Chem. Int. Ed. 2014, 53, 5959.

(27) (a) Lipshutz, B. H. Chem. Rev. 1986, 86, 795. (b) Faul, M. M.; Huff, B. E. Chem. Rev. 2000, 100, 2407.

(28) Zhang, D.-Y.; Zhu, F.-L.; Wang, Y.-H.; Hu, X.-H.; Chen, S.; Hou, C.-J.; Hu, X.-P. Chem. Commun. 2014, 50, 14459.

(29) Padín, D.; Cambeiro, F.; Fañanás-Mastral, M.; Varela, J. A.; Saá, C. ACS Catalysis 2017, 7, 992.

(30) In general, amines, as good nucleophiles, have tendency to trap inmmediately the diazocompound used, both in intraand intermolecular processes, avoiding CAM processes.

(31) González-Rodríguez, C.; Suárez, J. R.; Varela, J. A.; Saá, C. Angew. Chem. Int. Ed. 2015, 54, 2724. 


\section{Biosketches}

Carlos Saá, born in Lugo (Spain), studied chemistry at the Universidad de Santiago de Compostela
(Spain) where he received his PhD in 1985 under the supervision of Profs. L. Castedo, R. Suau and J. M.
Saá. He spent two-year (1987-1988) as a NATO postdoctoral research associate at the University of
California, Berkeley, working with Prof. K. P. C. Vollhardt in a Cobalt catalytic approach to ergot
alkaloids. In 1990, he joined the faculty at the Universidad de Santiago de Compostela as Profesor
Titular, and since 2004 has been a full Professor. His research interest centers on the discovery of new
methodology of organometallic catalysis and their applications to the synthesis of bioactive
compounds and organic conductive materials.

\section{Biosketches}

\begin{tabular}{|l|l|} 
Jesús A. Varela was born in 1971 in Lugo, Spain, and studied chemistry at the Universidad de Santiago \\
de Compostela, Spain. He completed his M. Sc. in 1994 and his Ph. D. thesis in 1999 (excellent award) \\
both under the supervision of Prof. Dr. Carlos Saá for research on synthesis of oligopyridines via cobalt \\
chemistry. He spent a predoctoral research training period in Harvard University under supervision \\
of Prof. Dr. Matthew Shair working on polyol synthesis by C-H insertion of metal-carbenes. From 1999 \\
to 2001, he spent a postdoctoral period as an Alexander Von Humboldt and Marie Curie Fellow with \\
Prof. Dr. Paul Knochel at Ludwig Maximilians Universität in Munich (Germany), working on remote C- \\
H activation via hydroboration. After that, he joined the faculty at the Universidad de Santiago de \\
Compostela as Ramón y Cajal researcher, and since 2008 as Profesor Titular. His research interests \\
are focused in organometallic catalysis towards the synthesis of biological active systems or molecular \\
materials and its mechanistic study.
\end{tabular}

\section{Biosketches}

Damián Padín received his B.Sc. degree in Chemistry from the University of Santiago de Compostela
in 2013. Then, he also obtained the M.Sc. in Advanced Chemistry from the same university in 2014
under the supervision of Prof. Carlos Saá and Prof. Jesús A. Varela. After a short research stay in Boston
College working on copper-catalyzed transformations under the supervision of Amir H. Hoveyda in
2017, he got his PhD in Organic Chemistry in 2019 under the supervision of Prof. Carlos Saá and Prof.
Jesús A. Varela for research on catalytic ruthenium vinyl carbenes. His research interests include the
development of new catalytic transformations, elucidation of reaction mechanisms and total synthesis.

